\title{
THE INCLINATION OF TREND FOLLOWING OF YOUTH OF PAKISTAN ON SOCIAL MEDIA
}

\author{
Sadaf Ghaffar \\ Department of Media Studies \\ Sindh Madressatul Islam University Karachi
}

\begin{abstract}
This research study has done to identify the impact of latest trend following running over social media on the life of youth and to investigate the major factors behind the addictive following habits of social media trends by the youth of Pakistan and what kind of effects they have to face on various aspects of their lives due to this much consumption of social media activities also to check out the ratio of social media latest trend following by the youth. In this research paper, the researcher has applied Quantitative type of methodology to conduct this study. The researcher has selected Pakistan as the universe of the study and the sample size is 80 . The data has collected in the manner of survey forms filled by the youth who belonged to different cities and places of Pakistan; aged from 15 to 30. This research study raises major points related to the extreme following of social media trends which includes the less sleeping time, impacts on real life relationships and disturbance in routine works. As this research study is based on Quantitative methodology, the data has collected by doing survey in the form of a well-designed questionnaire which were sent randomly to the youngsters by means of online in order to know their point of views about the latest social media trend followings and to get the accurate results with the help of using SPSS software. The researcher has tried to clear each and every point in an easy, formal and matured way. The data has collected in a fair and authentic manner without any involvement of biasness and objectivity from the researcher.
\end{abstract}

Keywords: Impact, Inclination, Social media trends

1.sadafghaffar7@gmail.com 


\section{INTRODUCTION}

Internet highly affected the way we work, we play, we interact, we discover, we live and our ways of consumption of anything for our physical and mental health. However, we don't have a concept in this mobile world to discover about the discoveries and innovations that from where all of these came and what are these things doing to us.

However, in the era of innovations and mechanization, as we all know that social media is playing a significant role in transforming our lives whether in an affirmative or negative manner. Social media provides us a number of platforms for every purpose and goals we want to achieve. For instance, if we want to watch movies, dramas or other entertaining content, we can search it and watch it free online, we can listen to songs, check out the events and sports happening on monthly, weekly and daily basis. It helps us in our educational process as well. Student of every age can get information and knowledge from anywhere around the world, people don't wait anymore to get a daily or weekly basis newspaper to know the latest updates because the audience has been transferred from print to electronic and digital media and nowadays, most of the news updates first crack on the social websites before break through any other medium.

However, they are so many platforms available on internet to make all this happen and it's a fact that not only common people are fond of using social media, but the politicians, celebrities and other public figures also use it to share their plans and other news worthy elements as it's the easiest and fastest way to convey their messages to the world. Well, the youngsters are highly participating these days in the social world as they are eager to know more about the world and for the purpose to engage today's youth, the mind gamers of social media launch a variety of social networking sites as they have immense knowledge about what the world want to see, hear and know. There's a wide array of social networking websites and applications exist on the internet for every purpose and each site offers community members different ways to network with one another. For instance, Facebook, WhatsApp, Twitter, Instagram, Skype, YouTube, Snapchat, Tik Tok, Airlift, Daraz. pk and Google itself is the highest rated search engine which provides solution for every problem anywhere and everywhere.

\section{Social Media Latest Trends}

Nowadays, one of the most trending parts of almost every social media platform is Meme. Meme refers to a video, gif or picture that explains a funny story or poke a fun at a cultural symbol or social idea about any moment of life. Every day billions of users share billions of memes for just fun and entertainment purpose.

Tik Tok videos are also the most trending part of social media nowadays and most popular among the younger generation. It is 15 seconds video that contains music, comedy, skits, acting, drama, dance and everything that is available for entertainment over the internet.

On the off chance that you are searching for some one of a kind and creative videos 
for making some fun video then you should try challenging videos. Nowadays, it is becoming bread and butter of social media. It is video challenge that a celebrity performs and post it on his social media account and challenge their fans and other celebrities to perform that video again. Examples are bottle cap challenge, ice bucket challenge, mannequin challenge etc.

GIF stands for graphic interchange format. They are now more popular than ever before. GIFs are pictures but in animated form. It represents a meme or also use for communicating jokes, emotions or ideas. It is very easy to create a gif and also many mobile apps like Facebook or WhatsApp already had an option for sharing a random or your desired gifs as a comment or newsfeed content.

After gifs let's talk about boomerangs. Basically boomerang is a throwing tool when thrown which intended to turn about a pivot opposite to the direction of its flight. In the same manner boomerang is a mini video that plays forward and backward. Boomerangs is a fairly new app spread widely by social media giant Instagram.

Some of the most trending parts of YouTube are roasting videos. Most of YouTubers earn fame and subscriber by creating such videos. In these videos, a particular object or a person is being joked and made fun by discussing their personal life or about the content they create and share. It's good that YouTube now has better terms and conditions for harassment and cyber-bullying.

Reaction videos are also the most trending part of social media. The basic definition of a "reaction video" is one where the subject is responding emotionally to some other video they are watching. It is the simplest and easiest way to catch some others popular content views by just video of just the reaction on that content.

Prank videos are funny social experiments and now very trending on social media and very popular among young and adults. In these videos people make practical jokes with family, friends on even with the people on the streets. A lot of people got fame on social media by just doing pranks videos and gained millions of followers and subscribers.

V-logs are becoming a huge part of social media like YouTube. It refers to video blogging in which v-log creator is providing insight into their life, suggestions, reviews, interests and thoughts. V-loggers film different parts of their daily routine whether they are at a common place, such as getting ready, doing breakfast, or energizing, exciting or visiting some adventurous places or events.

Selfie refers to a picture of one-self by own self. With the help of front camera in smart-phones which can be called as another innovation in modern world of technology, people can capture pictures of their own whether alone or with a family or friends gathering. Everyone in the world loves to hear good compliments because somehow such kinds of things satisfy people from inside especially when it's about their looks. Nowadays, with the help of a wide variety of modified applications, people are now able to apply different colored effects or might change their face cuts and can add cuteness by applying some funny cartoon faces in their selfies and post it on their social media accounts on which they get hundreds and thousands of 
likes, reactions and comments which satisfy them even more than someone's face to face compliments. Who doesn't want to see a "better-quality" version of oneself and being complimented on that by others, but making it a trend is a different matter.

The latest trends of social media which are mentioned as above are quite common and highly following by the youth, not only in Pakistan but overall around the world. There are so many positive and negative effects of these trends for instance; in a negative perspective, some people skip their meal times just because of using Facebook, some bunk their school, college and university classes even office works in order to go somewhere for making a v-log, some skip family or friends gatherings just because they love spend more time on social media, some sacrifice their sleeping times just to watch memes, some ignore and neglect their parents as well as teachers' obligations just because they focus more on the comments they get over their Facebook pictures and status, and even some encounter real life accidents just in order to make Tik Tok videos and taking selfies while standing at the edge of a mountain, a huge building, a bridge over riverside, or even while riding a bike on a busy road. On the other side, some people get fame by the videos they make on Tik Tok, some earn money by making videos for YouTube and some consider it a source of problem escapism because they become stress-free after watching funny memes and videos right after spending a whole day filled with real life tensions and problems. By conducting this research study, the researcher wants to see the impact of these trends on youth's real life whether in a positive manner or negative manner. Also to check out that is the youth really getting addicted to social media more due to these social media trend following. The researcher also aims to check out the ratio of trend following by the youth.

\section{Objective}

To determine the effects of Social Media Trends especially on the youth of Pakistan, as they spend a lot of time on social media nowadays and also participate in different activities running on social media. Latest trends are creating both positive as well as negative impact on the routine life of the youth. The main reason to conduct this study is to identify the ratio of both types of effects, in order to analyze that if social media trends are playing either more positive or more negative role in youth's life. Another objective is to identify that if the social media addiction rate is increasing or decreasing due to following these latest trends.

\section{Research Questions}

RQ1: Do people become more social on social media as compared to real life?

RQ2: Do the youth become more addicted to social media due to the latest trend following?

RQ3: Do the latest trends running on social media are somehow beneficial for the youth in real life?

RQ4: Do the social media trends work as a source of problem escapism in their real life?

RQ5: Do the latest trends on social media affect Pakistani youth more in a negative manner?

Hypothesis 
H1: Social media latest trends affect the life of youth more in a negative manner. H0: Social media latest trends affect the life of youth more in a positive manner. $\mathrm{H} 2$ : The social media addiction rate is increasing due to the latest trend following on social media.

H0: The social media addiction rate is decreasing due to the latest trend following on social media.

\section{Operational Definitions \\ Impact}

In this research study, 'Impact' refers to the best and the worst effects of social media latest trends on youth's life. In how many ways social media trends and activities influence their lives; and the factors behind this much influential impact.

\section{Inclination}

In this research study, the word 'Inclination' is used as "the fact, degree or ratio of liking something or having an interest in something".

\section{Social Media Trends}

In general, a trend can be referred as 'variation, change, style, mode, craze, mania or fashion'. So in the light of this research study, the term 'Social Media Trends' can be explained as "The changes, variations, styles, fashions, craze, modes or mania of different social media activities which are followed by a massive group of people and well-known by all".

\section{LITERATURE REVIEW}

The advance and improved usage of social media structures together with Whatsapp, Facebook, Twitter, Instagram and many others and has end up a global phenomenon for quite a while. A study by means of Young, b (2006) observed that the internet has quantity its wings to acquire teenager's faculty lifestyles and it was likewise seen by a researcher Young that understudies was a progressively subject to web to get the data that relates their scholarly life just as diversion.

Nicole B,Ellison, Charles Steinfield and Cliff Lampe in 2007 researched on "The Benefits of Facebook Friends, Social capital and College students use of online social network sites" .The results indicated that those students who were the less interface with Facebook faced interaction issues they have lower social capital bridge with other students as compared to those who has used Facebook more strongly.

Soraya Mehdizadeh researched on the topic "Self-Presentation 2.0: Narcissism and Self-Esteem on Facebook" and published a research based article on 16th August, 2010. The sample were collected from 100 Facebook users at York University and the research explained the facts about how people represent their personalities and identities on the specific social networking platform Facebook and what strategies they apply to promote their Facebook pages which are usually based on selfpromotional content. Gender differences were also found to influence the type of self-promotional content presented by individual Facebook users. 
Sitaram Asur, Bernardo A. Huberman, Gabor Szabo and Chunyan Wang (2011) explained in their research that very few contents manage to grab the attention of the audience on social media to rise to the top and later become temporal social media trends which are displayed to the users. The formation, persistence and decay of trends are also being explained on the basis of theoretical perspective regarding an intensive study of trending topics on Twitter. The depth of the connection between the content and the users on social media plays a major role in creating latest trends. Rideout, V. (2012) stated that the adolescents are investing more energy in online networking only for excitement reason. She told that an American tyke a normally goes through 7-8 hours per day only for amusement and as a rule, perform multiple tasks between various interpersonal organizations they use.

Pardo A (2013) has endeavored to clarify internet based life's significance in understudy's life. He said that such stages enable understudies to speak with one another for sharing data, information and ideas. Pardo also states that such sort of collaborations create a vital area for the individuals to learn unique things.

Shahjahan ATM; and Chisty KU (2014) reached a resolution that a general impact of internet based life on young people is contrary. As a result of dependence on social stages, understudies normally get low evaluations. Guardians don't know about their kids' social records and their strategies, which influence them later on. The young person needs certainty and attempt to stay away from close-ups and personal interchanges.

Khurana N', a research scholar at Amity University in Noida-201301, UP, India published a research article about "The impact of social networking sites on the youth" on December 3, 2015 in Journal of Mass Communication and Journalism. This research study aims to create a lot of awareness between the youth related to social networking sites and the findings and results did not only expose the negative and positive factors of the usage of social media that are affecting the youth but also explained the ways to use these sites wisely. The researcher further explained that it has now become cleared that people nowadays are being too much insensitive that they're engrossed into their phones at the worship places, homes, and educational institutions; even at the roads and highways that they do not even focus on their significant things of life. They do not even care whether parents, relatives and guests are around. Their priorities have become changed and their attention has actually been moved from the real world to the virtual world.

Singh T and Siddiqui S (2016) talked about equally positively and negatively parts of online networking. They explained that social media has become the most significant part of people's life these days as it provides a numerous variety of things regarding people's interests by with they can transform their lifestyles within no time. In this paper, they covered all the aspects of social media that how the social media impacts various fields of the society such as education, business, youth etc in a broad way. Understudies can be influenced by a gathering of their class on any social stage where they can talk about their same interests and choices. They can also share helpful data by utilizing that explicit stage and can also investigate the new doors for their future. However, it likewise diverts understudies from 
their scholastics. Social media has increased the quality and rate of collaboration especially among students. Social media is also helpful in business affairs to enhance an organization's performance in various ways such as to accomplish business objectives or in increasing annual sales of the organization. Youngsters are seen addictively using social media on daily basis. Also, the youth get addicted to abuse by making counterfeit records for entertainment purpose only and theyfar alongget dependent on it. Social media has various advantages but it also has some disadvantages which affectpeople more in a negative manner. False information can lead the education system to failure, in an organization wrong advertisement will affect the productivity, social media can abuse the society by invading people's privacy, some useless blogs caninfluence youth that can become violent and can take some inappropriate actions. Use of social media is beneficial but should be used in a limited way without getting addicted.

Two researchers and professors of Computer Applications Department at GDC Mendhar in Poonch, India namely W.Akram and R.Kumar published a research study on 30th October, 2017 in JCSE (International Journal of Computer Sciences and Engineering) which was about "A Study on Positive and Negative Effects of Social Media on Society". The researchers generate the idea that social networking sites effects are twofold. The positive side explains that social network can be used efficiently in a productive way by the professionals as an invaluable tool to achieve their business goals and to promote their skills and the negative side is associated with a huge quantity of risks which can harm human life in worst manner. The main focus of this research paper is to highlight the particular fields such as health, education, business, society and youth and researchers have come up with the facts that in how many broader ways these media is affecting the society.

\section{RESEARCH METHODOLOGY}

Quantitative research method is applied to this research study because the topic of the research has to deal with the ratio of people having effects of latest social media trends running online these days on their real life routine affairs. This research study is based on the survey method in which random sampling method is used. A questionnaire which occupies 28 questions was circulated online through various mediums and the survey was taken after getting all of the questionnaires filled out. As the topic of this research study is "The Inclination of Trend Following of Youth of Pakistan on Social Media" purposely conducted to find out the rate of trend following over social media by the youth of Pakistan. Which of the social media platforms they use the most? Which of the social media trends they often follow on daily basis? Which of the social media trends they create on their own? What are the major factors involved in creating such trends? And what are positive and negative effects of following such latest trends over social media on their real life situations. To identify youngsters' responses is highly important because nowadays, the involvement ratio of the youth of Pakistan into social media trends is increasing day by day. To get to know the point of views of the youth is compulsory in order to understand the major cause and effect behind the conditions of being involved and participating in latest social media trends. 
80 people including male and female from the youth were randomly selected as the sample size of the research and the universe is Pakistan. Age from 18 to 30 is considered as the age limit of the youth in this research study. The aim of this research study is to explore the effects of creating and following social media trends whether positive or negative on the life of the youth of Pakistan.

Data Analysis and Findings

The data which was primary collected by means of online questionnaire sent and filled by 80 respondents was later successfully and authentically put on the SPSS (Statistical Package for the Social Sciences) software version 22 by which the researcher got accurate results which are analyzed in the form of frequency tables, pie charts, bar charts, cross-tabulations and chi square test tables as mentioned below

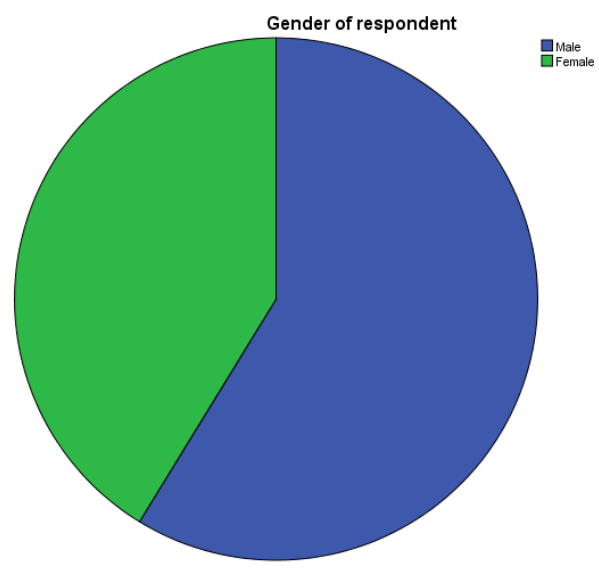

Figure 1

This pie chart shows that out of 80 respondents, 47 were males and 33 were females. The ratio calculated in percentage as $58.8 \%$ were males while $41.3 \%$ were females.

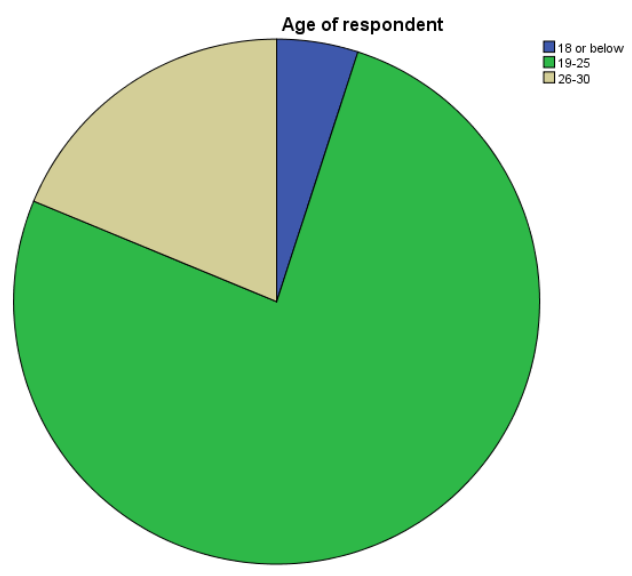

Figure 2 
The above frequency table and pie chart shows that more than half of the total sample size were belonged to $19-25$ age group which includes $76.3 \%$ of respondents, numerically 61 out of a total of 80 . While $18.8 \%$ were belonged to $26-30$ age group which includes 15 respondents and with the least percentage of $5.0 \%, 4$ respondents belonged to 18 or below age group.

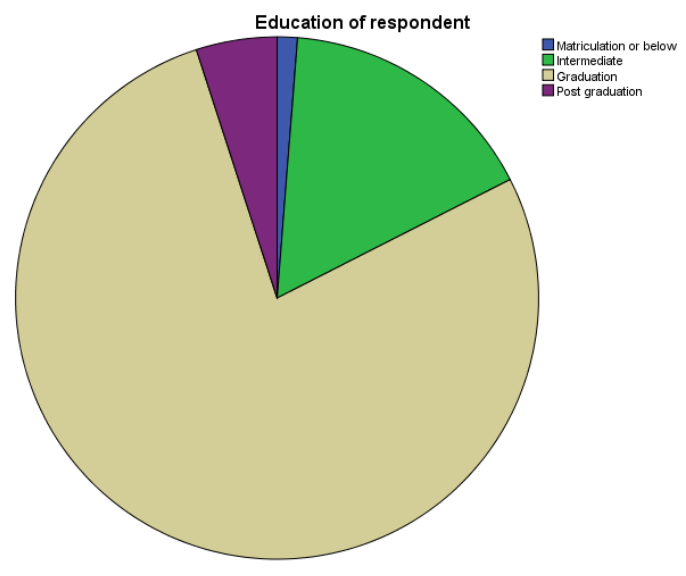

Figure 3

According to the education belongings, $77.5 \%$ of the whole sample size are graduated which includes 62 people from the youth. With a percentage of $16.3 \%$ have done with intermediate including 13 respondents. $5.0 \%$ belonged to post graduation level including 4 people and with a least percentage of about 1.3\%, 1 respondent out of 80 were on matriculation level or below.

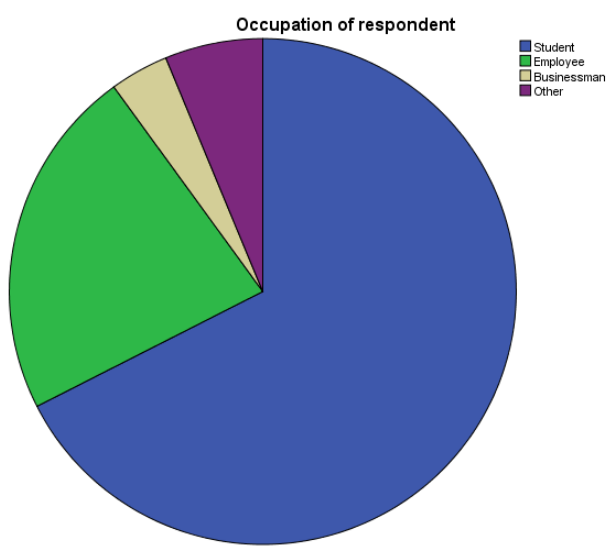

Figure 4

$67.5 \%$ of the respondents were students including 54 people, $22.5 \%$ were employees including 18 respondents, $3.8 \%$ are running their own business including 3 businessmen and $6.3 \%$ of the population size of the study belonged to other occupations including around 5 people. 


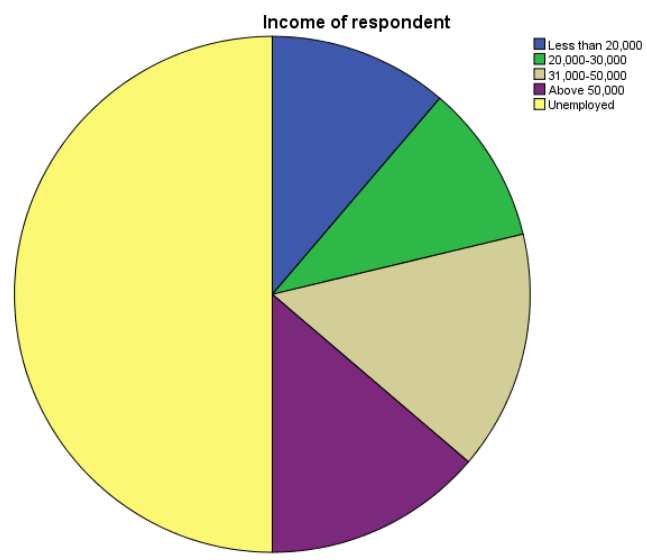

Figure 5

According to the income distribution of respondents, half of the population from the whole sample size is unemployed including $50.0 \%$ in ratio and around 40 respondents. Around $11.3 \%$ earn less than 20,000 including 9 respondents. $10.0 \%$ earn around 20,000-30,000 including 8 people. $15.0 \%$ out of the whole population earn 31,000-50,000 including 12 respondents and $13.8 \%$ out of $100 \%$ of the population earn above 50,000 which includes 11 respondents.

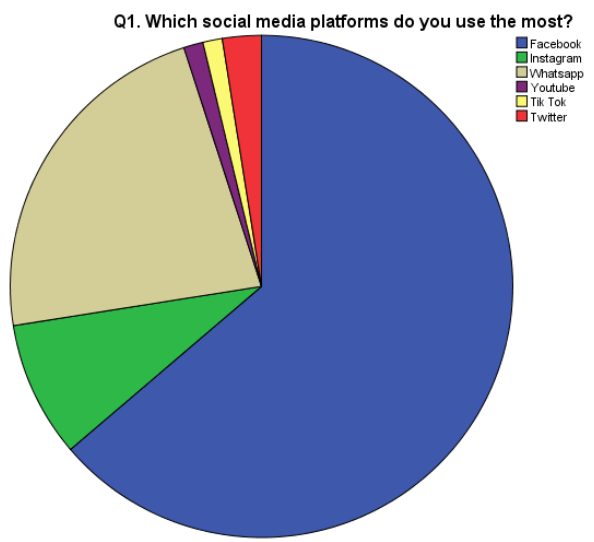

Figure 6

According to table 6 and figure 6, with a percentage of $63.8 \%$ out of $100 \%$ Facebook is the most highly using platform. WhatsApp comes on 2 nd number with a percentage of $22.5 \%$. Instagram with $8.8 \%$ comes on 3 rd rank. Then Twitter with $2.5 \%$ and YouTube and Tik Tok with a rating of $1.3 \%$ is the most less using platforms by the youth of Pakistan. 


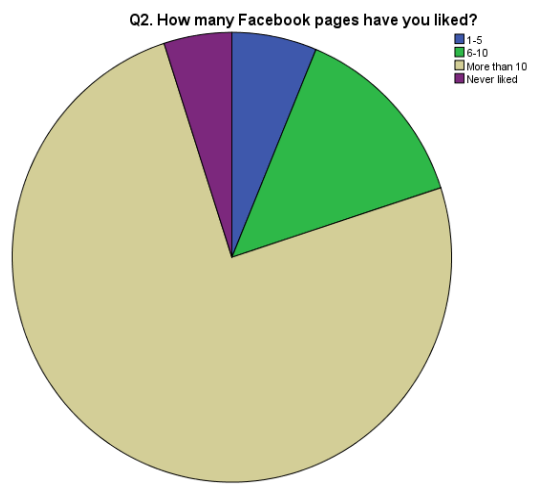

Figure 7

With a percentage of $75.0 \%$, more than 10 pages are liked by 60 people on Facebook. $13.8 \%$ respondents have liked $6-10$ pages. $6.3 \%$ people have liked $1-5$ pages and $5.0 \%$ people haven't liked any Facebook page out of 100\% respondents.

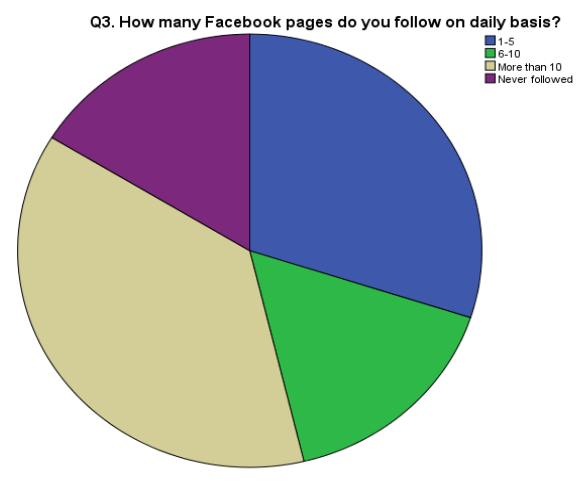

Figure 8

With a highest percentage of $37.5 \%$, more than 10 pages are followed by 30 people on Facebook. 30.0\% respondents follow 1-5 pages. 16.3\% people follow 6-10 pages and $16.3 \%$ people haven't followed any Facebook page out of $100 \%$ respondents.

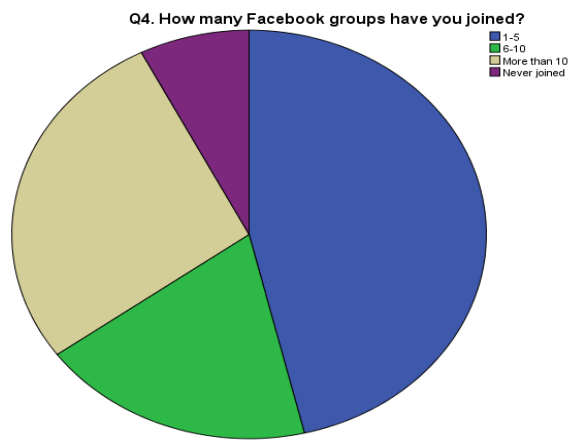

Figure 9 
With the highest percentage of 46.3\%, 1-5 groups have joined by 37 people on Facebook. 6-10 groups have joined by $18.8 \%$ of population. $27.5 \%$ respondents have joined more 10 groups and 7.5\% haven't joined any Facebook group.

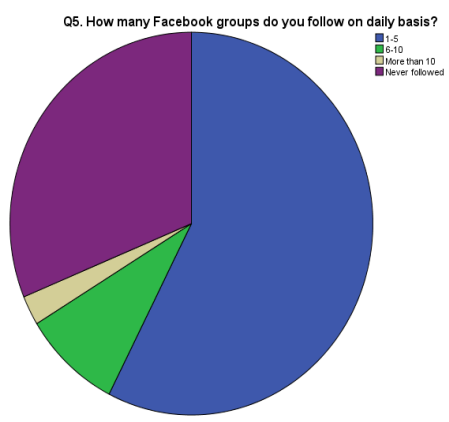

Figure 10

According to table 10 and figure $10,57.5 \%$ of the total population follow 1-5 Facebook groups, $8.8 \%$ people follow 6-10 groups, $2.5 \%$ follow more than 10 groups and $31.3 \%$ do not follow any Facebook group on daily basis

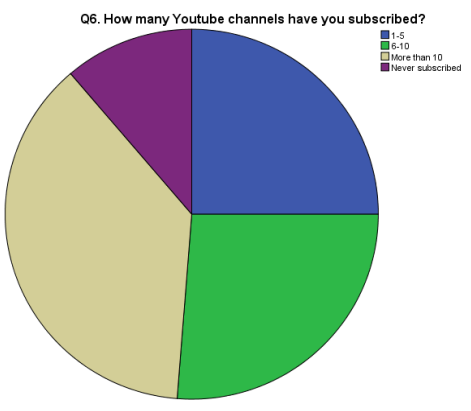

Figure 11

With a percentage of $25.0 \%$ of the whole population, 1-5 YouTube channels have subscribed. 6-10 channels are subscribed by $26.3 \%$ people. $37.5 \%$ of the youth subscribed more than 10 channels and $11.3 \%$ haven't subscribed any YouTube

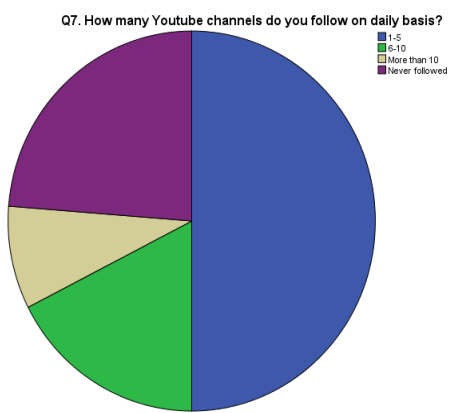

Figure 12

Half of the population with a percentage of 50\% follows 1-5 YouTube channels on 
daily basis. $17.5 \%$ respondents follow $6-10$ channels, $8.8 \%$ follow more than 10 channels and $23.8 \%$ population doesn't follow any YouTube channel

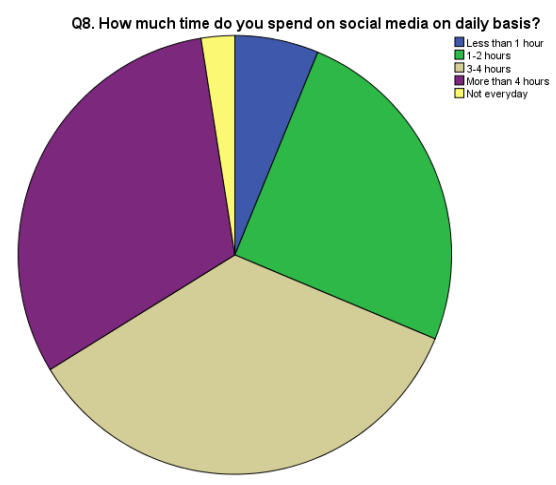

Figure 13

With the least percentage of $2.5 \%, 2$ people from the population don't spend time on social media every day. $6.3 \%$ people spend less than 1 hour on social media in a day. $25.0 \%$ spend $1-2$ hours, $31.3 \%$ spend more than 4 hours and with the highest percentage of $35.0 \%, 28$ people spend 3-4 hours on social media on daily basis.

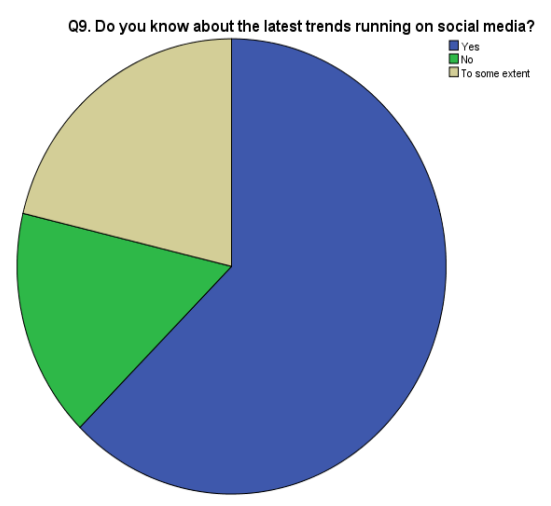

Figure 14

More than a half of the population with a percentage of $62.5 \%$ said "Yes" on knowing about the social media latest trends. 21.3\% said they know the latest trend to some extent. While with the least percentage of $16.3 \%, 13$ people from the youth said "No" about having knowledge of social media latest trends. 


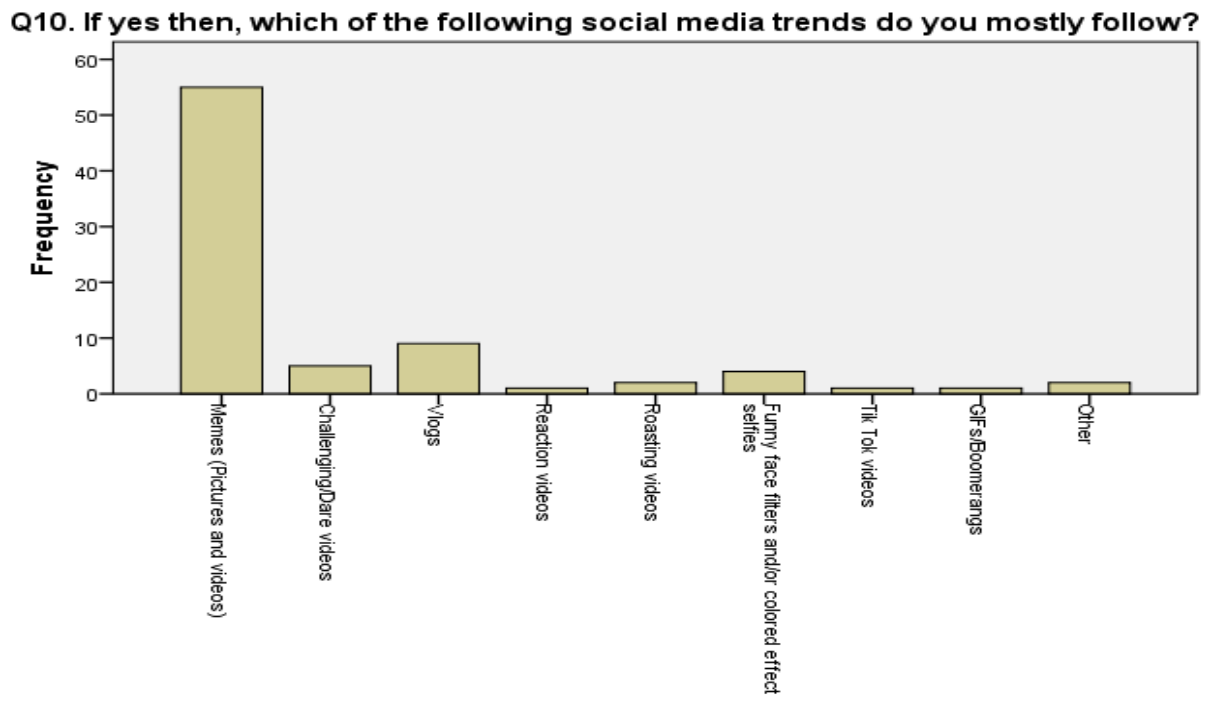

Q10. If yes then, which of the following social media trends do you mostly ...

Figure 15

With a highest percentage of about $68.8 \%, 55$ respondents follow "Memes" on social media $6.3 \%$ follow "Challenging/Dare videos", $11.3 \%$ follow "V-logs", $1.3 \%$ follow "Reaction videos" $2.5 \%$ follow "Roasting Videos", $5.0 \%$ follow "Funny face filters and/or colored effect selfies", $1.3 \%$ follow "Tik Tok videos", $1.3 \%$ follow "GIFs/Boomerangs" and 2.5\% follow other trending content on social media.

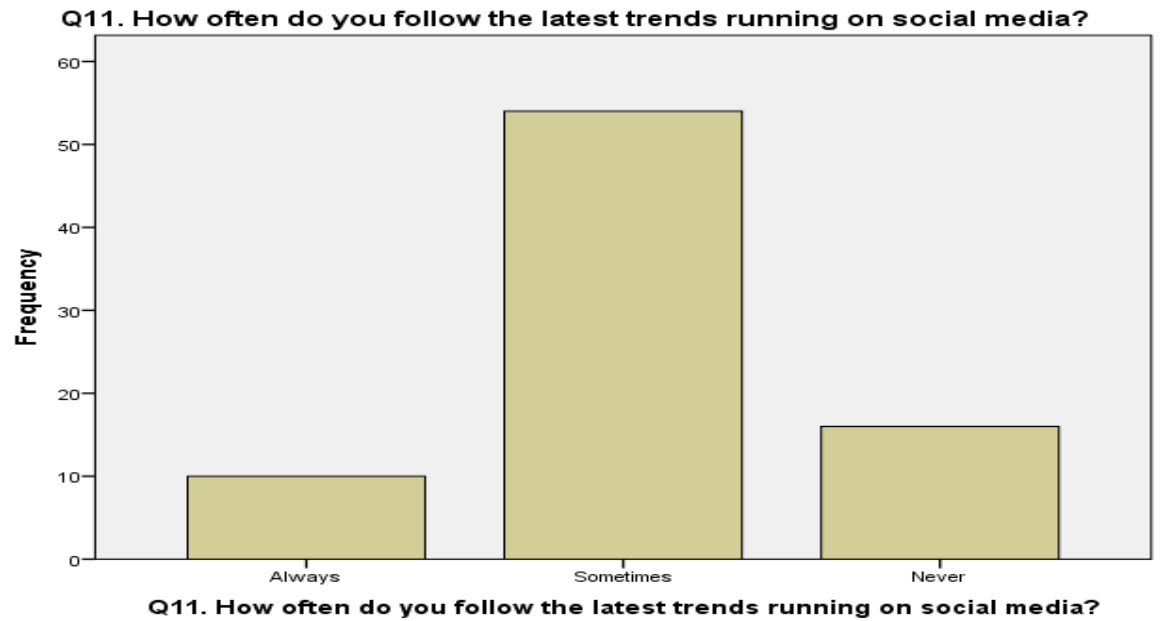

Figure 16

According to table 16 and figure $16,12.5 \%$ respondents said they always follow the latest trends $67.5 \%$ sometimes follow and $20.0 \%$ never followed any latest trends on social media. 


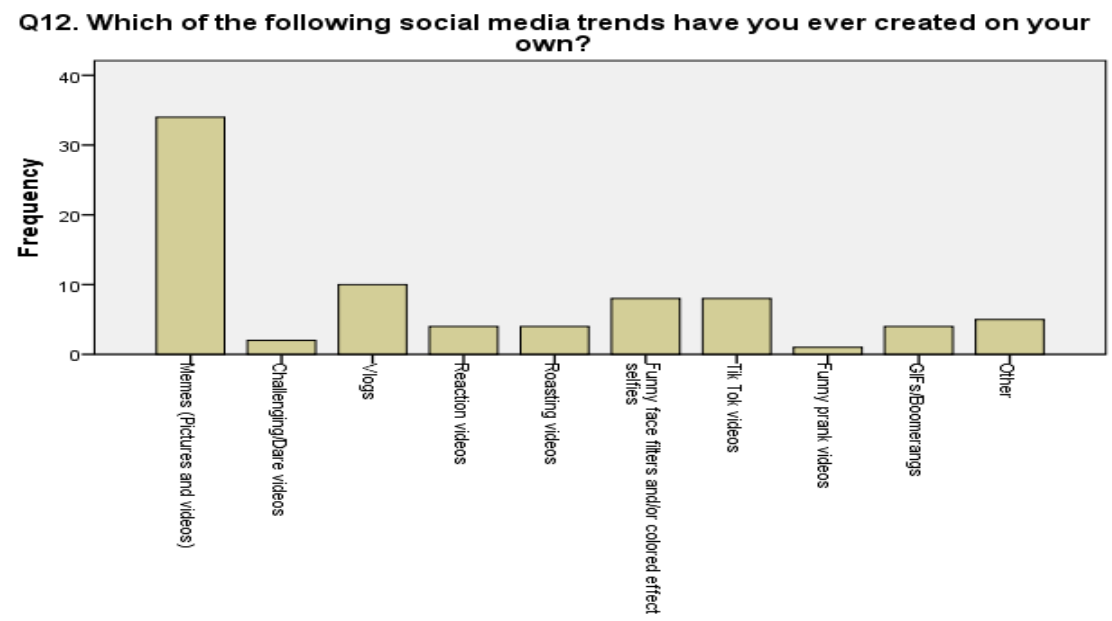

Q12. Which of the following social media trends have you ever created on ...

Figure 17

According to table 17 and figure 17, with the highest percentage of $42.5 \%, 34$ out of 100 respondents have created "Memes", 2.5\% have created "Challenging/ Dare videos", $12.5 \%$ have created "V-logs", 5.0\% have created "Reaction videos", $5.0 \%$ have created "Roasting videos", $10.0 \%$ have created "Funny face filters and/ or colored effects selfies", $10.0 \%$ have created "Tik Tok videos", $1.3 \%$ have created "Funny Prank videos", 5.0\% have created :GIFS/Boomerangs" and 6.3\% have created other latest trending contents for social media.

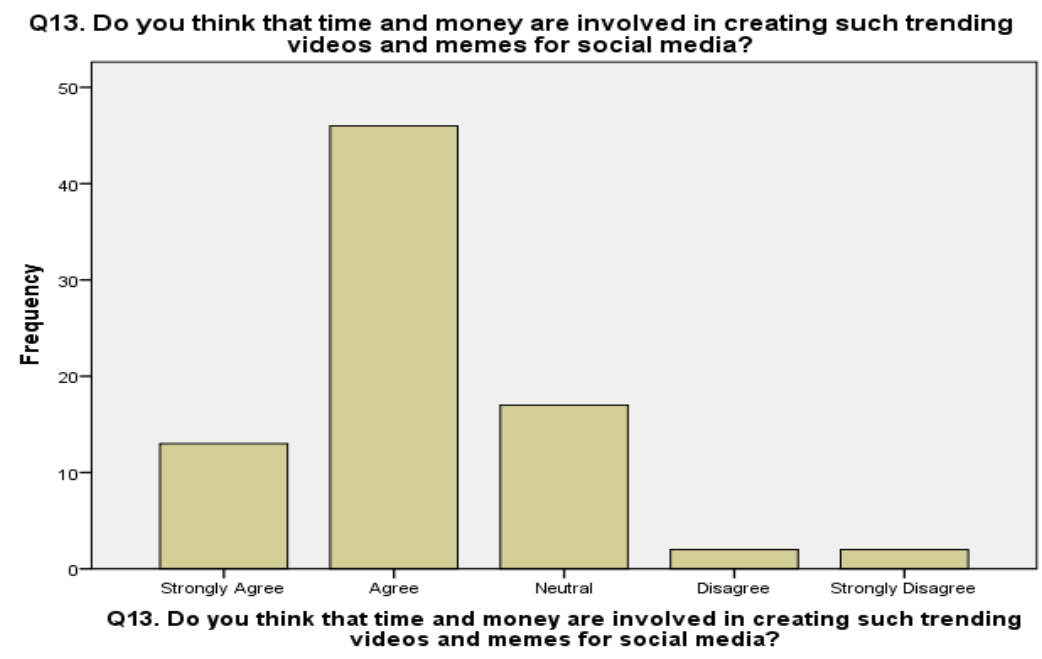

Figure 18

With a percentage of $16.3 \% 13$ people strongly agreed $57.5 \%$ agreed, $21.3 \%$ neutralized $2.5 \%$ disagreed and $2.5 \%$ strongly disagreed with the statement that time and money are involved in creating latest trending videos, memes and other content for social media. 


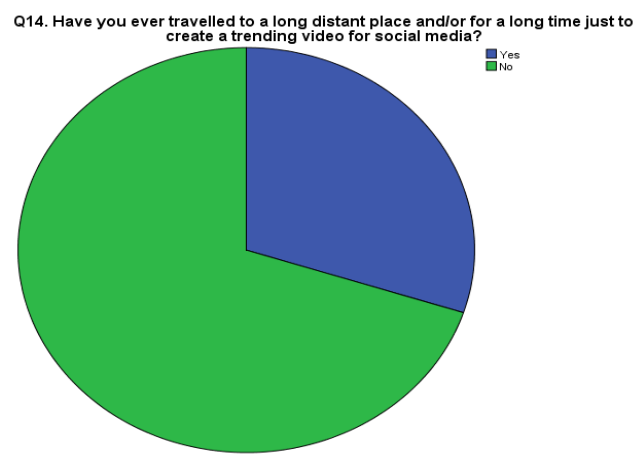

Figure 19

According to table 19 and figure 19, 80.0\% population said "Yes" and 70.0\% said "No" when they were asked about travelling to a long distant place and/or for a long time just to create any trending videos or content for social media.

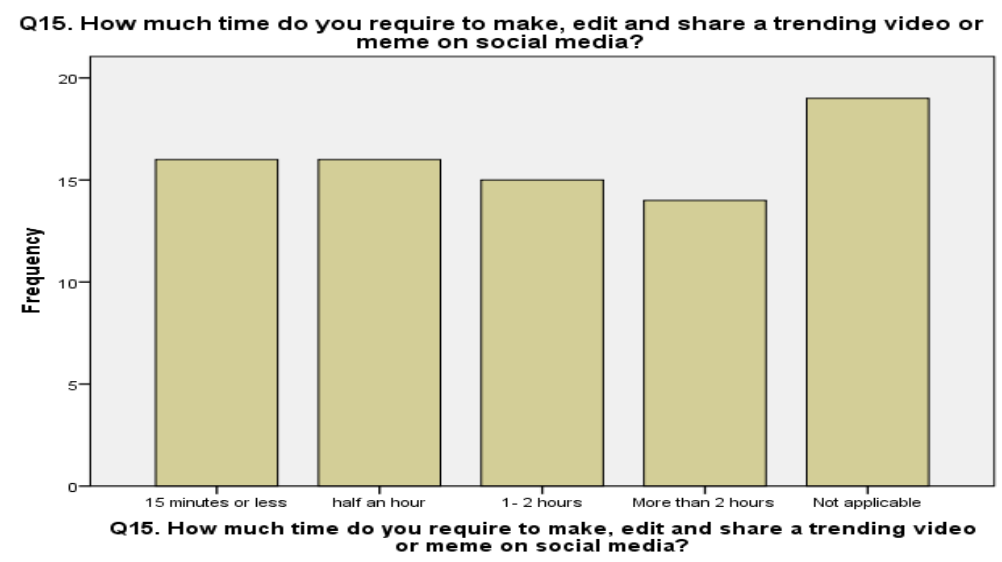

Figure 20

With a percentage of $20.0 \%, 16$ respondents said they require " 15 minutes or less" to make, edit and share latest trends.20.0\% require "Half an hour", $18.8 \%$ require " $1-2$ hours" $17.5 \%$ require "More than 2 hours" and $23.8 \%$ donate have any idea about how much time does it require to make, edit and share latest trends on social media. 


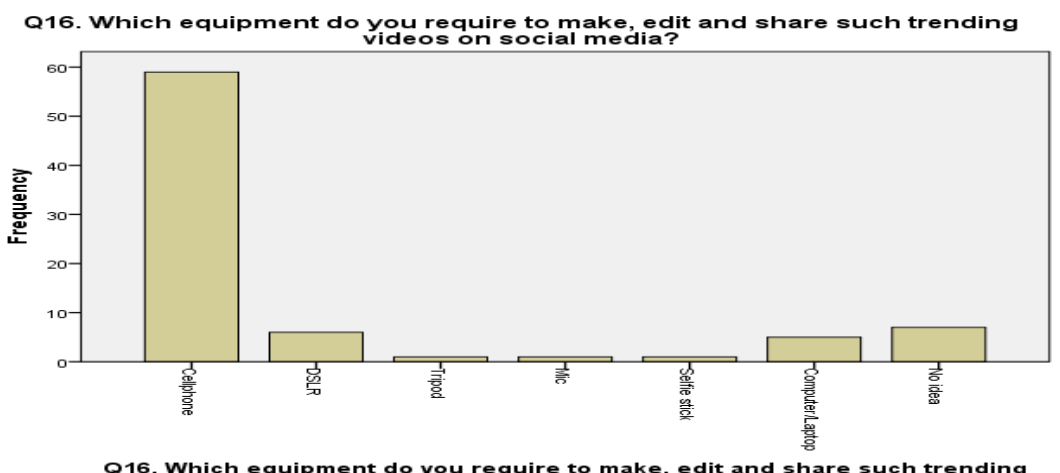

Q16. Which equipment do you require to make, edit and share such trending

Figure 21

$73.8 \%$ population requires "Cell-phone" to make edit and share latest trending content for social media. 7.5\% requires "DSLR", 1.3\% requires "Tripod", $1.3 \%$ requires "MIC", 1.3\% requires "Selfie-Stick", 6.3\% requires "Computer/Laptop" and $8.8 \%$ people said that they don't have any idea about it.

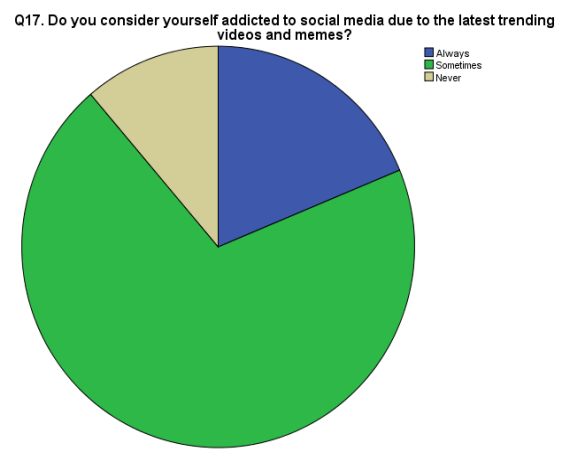

Figure 22

$18.8 \%$ people consider themselves always addicted, $70.0 \%$ sometime and $11.3 \%$ never got addicted to social media due to the latest trends.

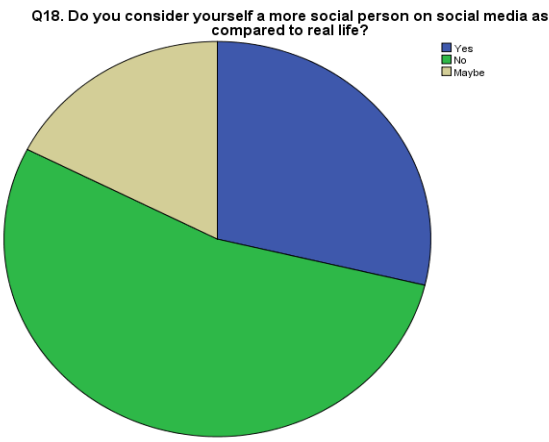

Figure 23 
28.8\% people go with "Yes", 53.8\% with "No" and 17.5\% with "Maybe" on considering themselves more social on social media as compare to real life.

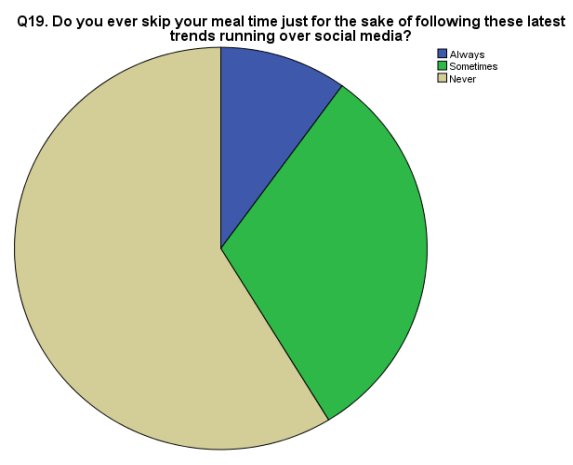

Figure 24

$10.0 \%$ people always, $31.3 \%$ sometimes $58.8 \%$ never skip their meal time just for the sake of following latest trends on social media.

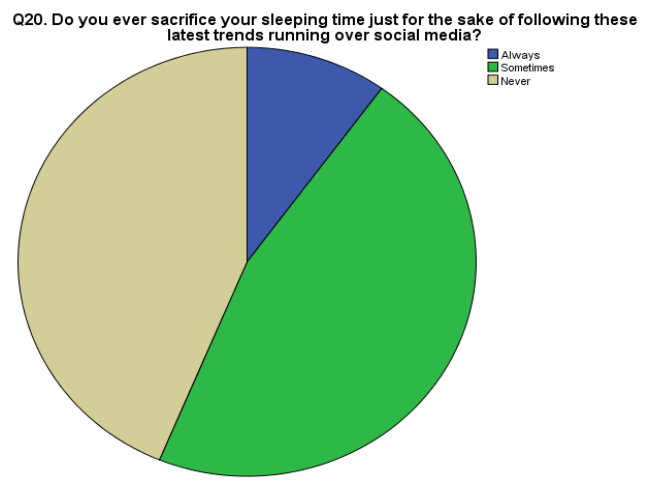

Figure 25

$10.0 \%$ people always sacrifice, $46.3 \%$ sometimes, $43.8 \%$ never sacrifice their sleeping time for following social media trends.

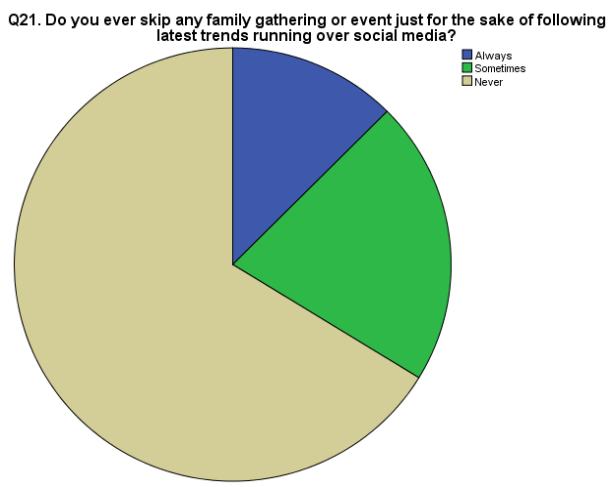

Figure 26 
$12.5 \%$ people always, $21.3 \%$ sometime and $66.6 \%$ never skip any family gathering just to follow social media trends.

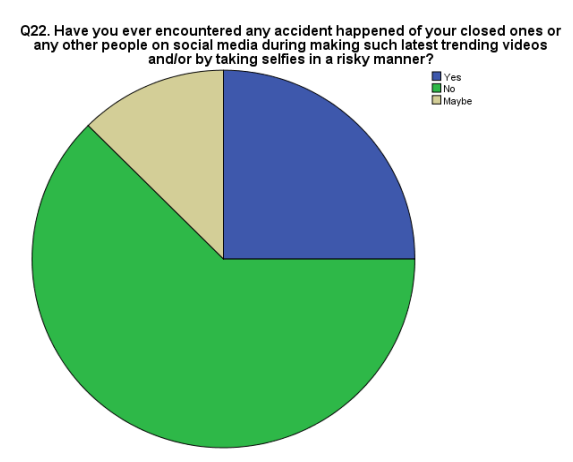

Figure 27

$25.0 \%$ people go with "Yes", $62.5 \%$ go with "No" and $12.5 \%$ go with "Maybe", when they were asked about encountering any accident happened during making latest trending content for social media.

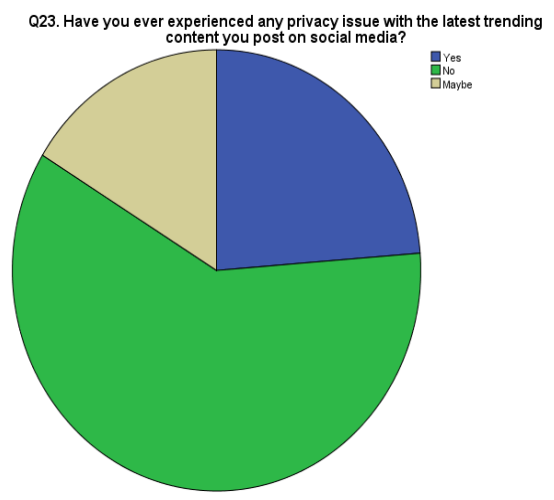

Figure 28

$23.8 \%$ people go with "Yes", $60.0 \%$ go with "No" and $16.3 \%$ go with "Maybe", when they are asked about facing any privacy issues due to the trending content they post on social media. 


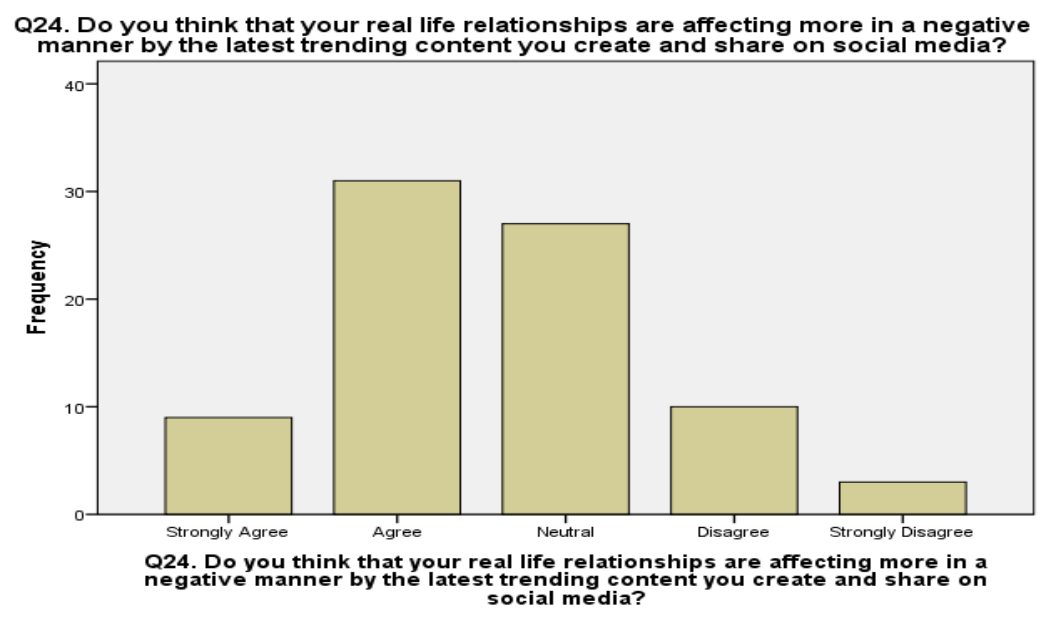

Figure 29

$11.3 \%$ people strongly agreed, $38.8 \%$ agreed, $33.8 \%$ neutralized, $12.5 \%$ disagreed and $3.8 \%$ strongly disagreed with the statement mentioned above in figure 29 table 29.

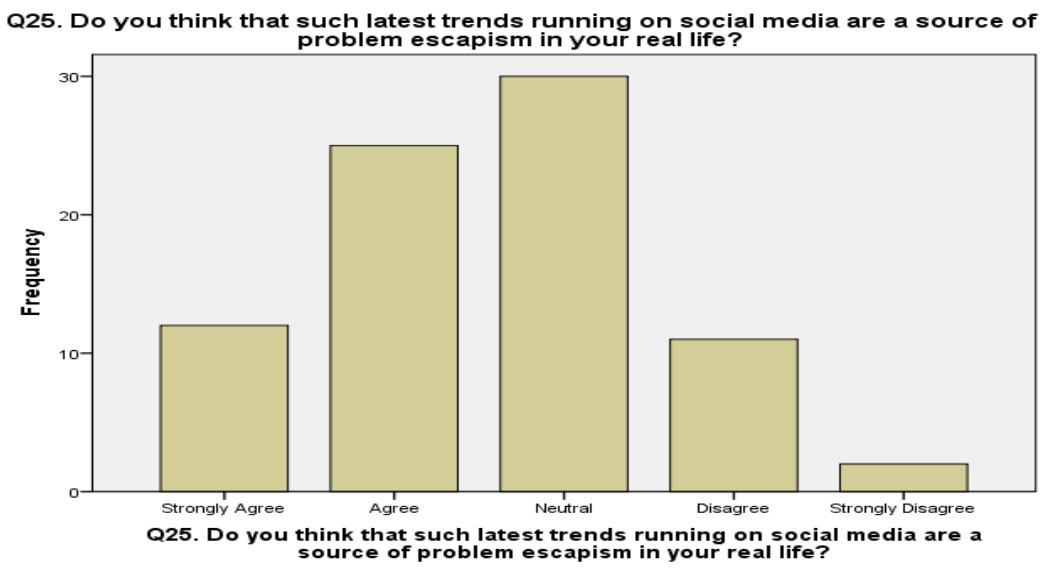

Figure 30

Latest trends on social media are a source of problem escapism. This statement is strongly agreed by $15.0 \%$ population, agreed by $31.3 \%$, neutralized by $37.5 \%$, disagreed by $13.8 \%$ and strongly disagreed by $2.5 \%$. 


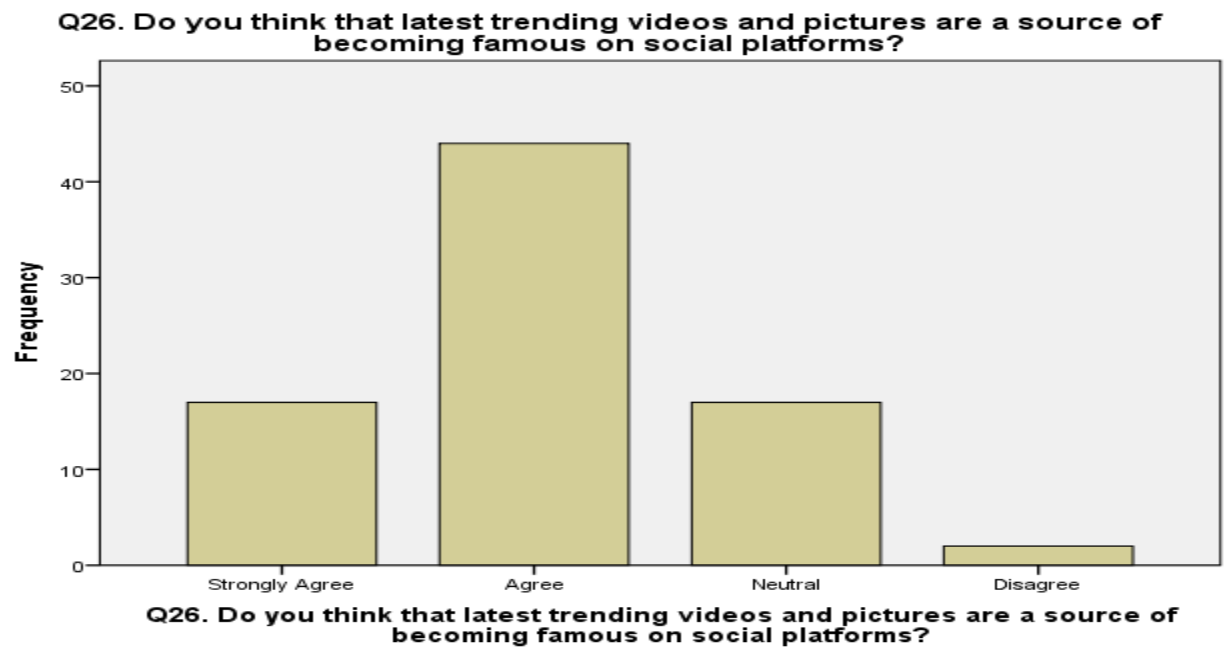

Figure 31

Latest trending videos and pictures are a source of becoming famous on social platforms. This statement is strongly agreed by $21.3 \%$, agreed by $55.0 \%$, neutralized by $21.3 \%$, disagreed by $2.5 \%$ and strongly disagreed by $0 \%$ people.

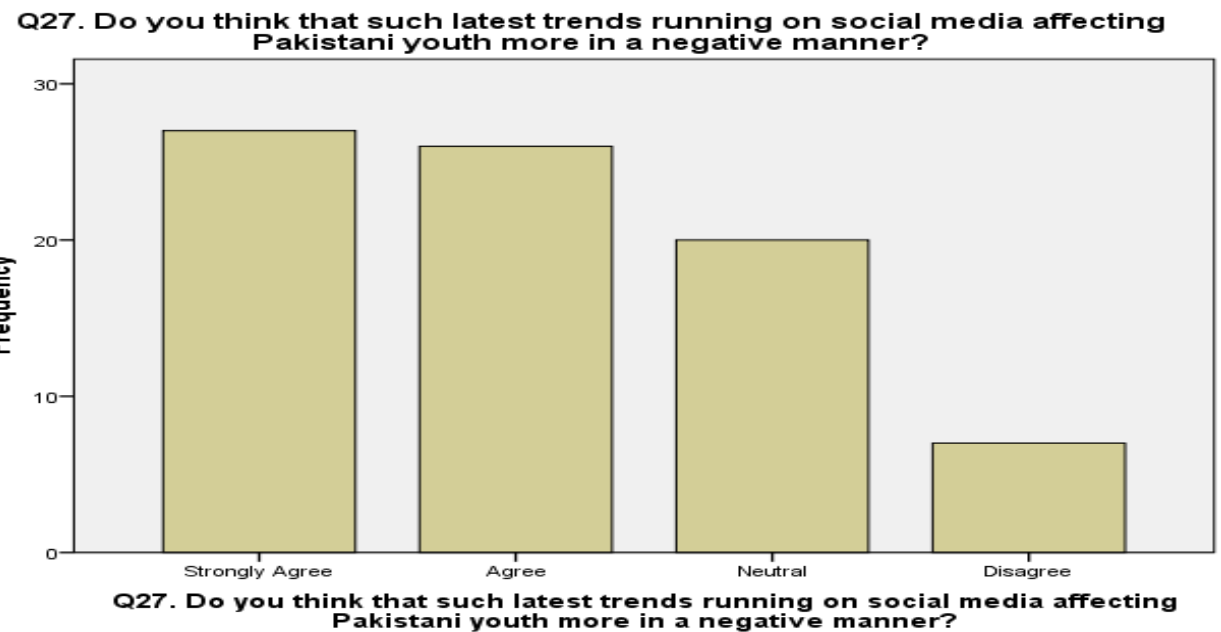

Figure 32

Social media latest trends are affecting Pakistani youth more in a negative manner. This statement is strongly agreed by $33.8 \%$, agreed by $32.5 \%$, neutralized by $25.0 \%$, disagreed by $8.8 \%$ and strongly disagreed by $0 \%$ people. 


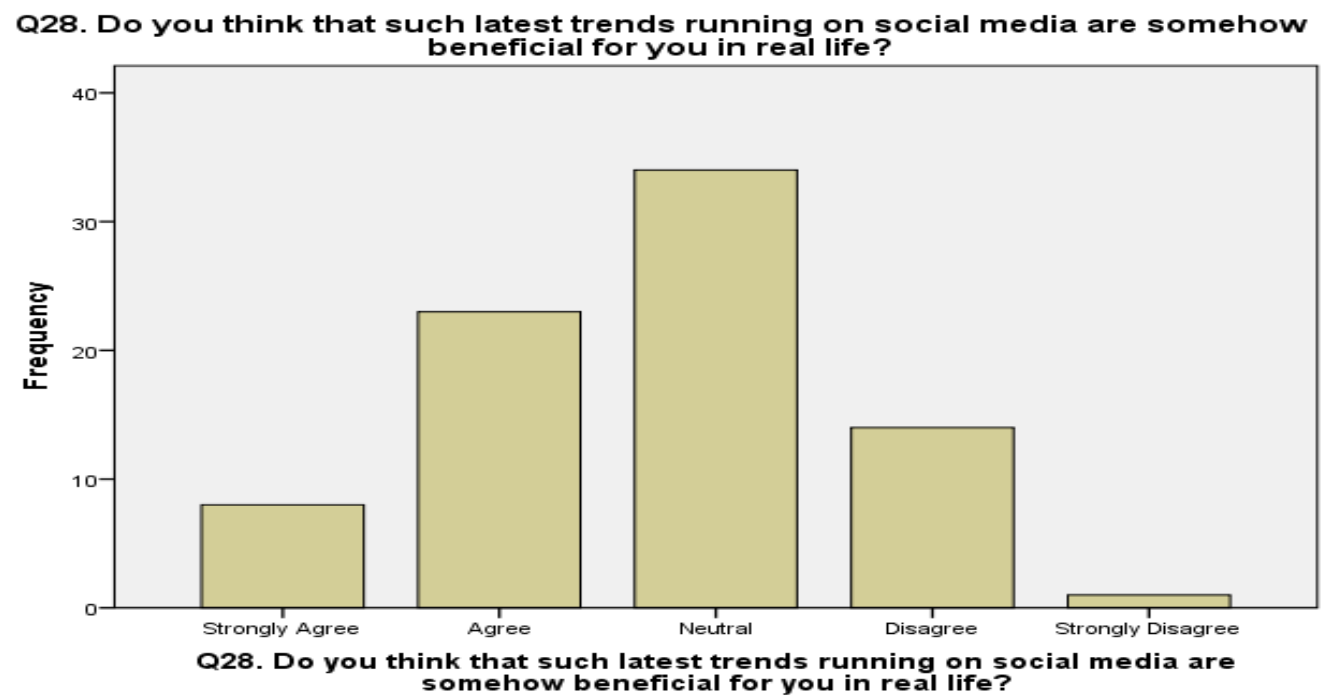

Figure 33

Social media latest trends are somehow beneficial for the youth in real life. The above statement is strongly agreed by $10.0 \%$, agreed by $28.8 \%$, neutralized by $42.5 \%$, disagreed by $17.5 \%$ and strongly disagreed by $1.3 \%$ people.

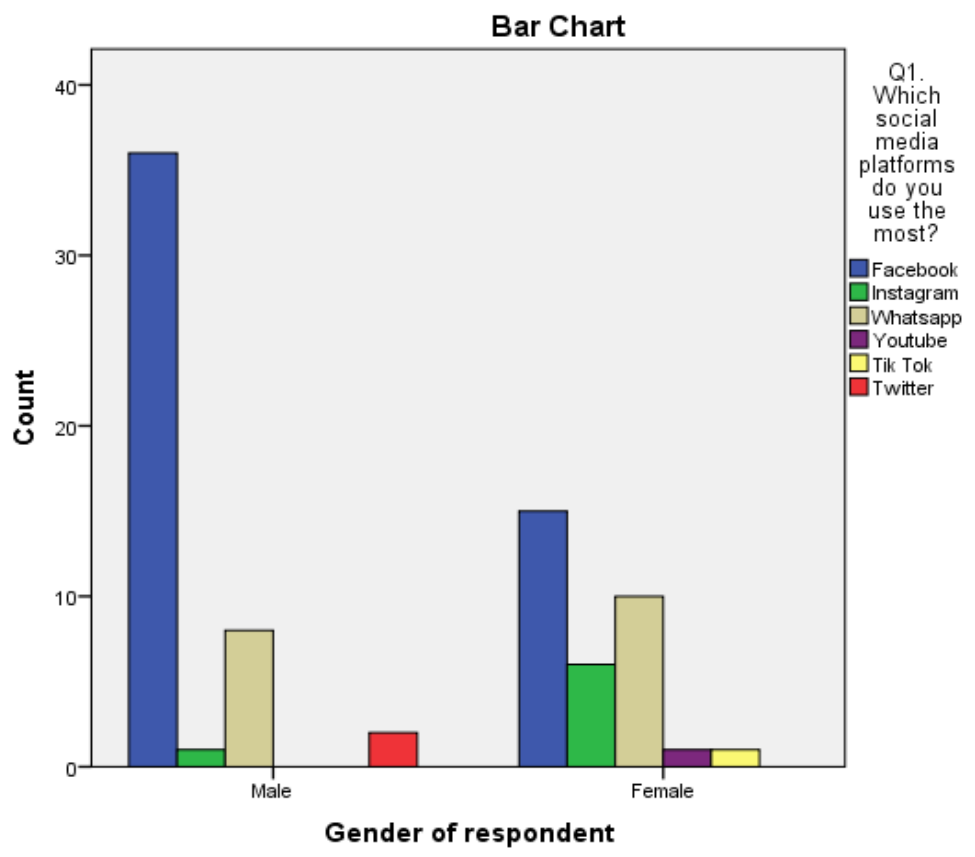

Figure 34

According to table 34 and figure 34, Facebook is the most highly using platform in both genders. 51 people mostly used Facebook out of 80 respondents including 36 
males and 15 females.

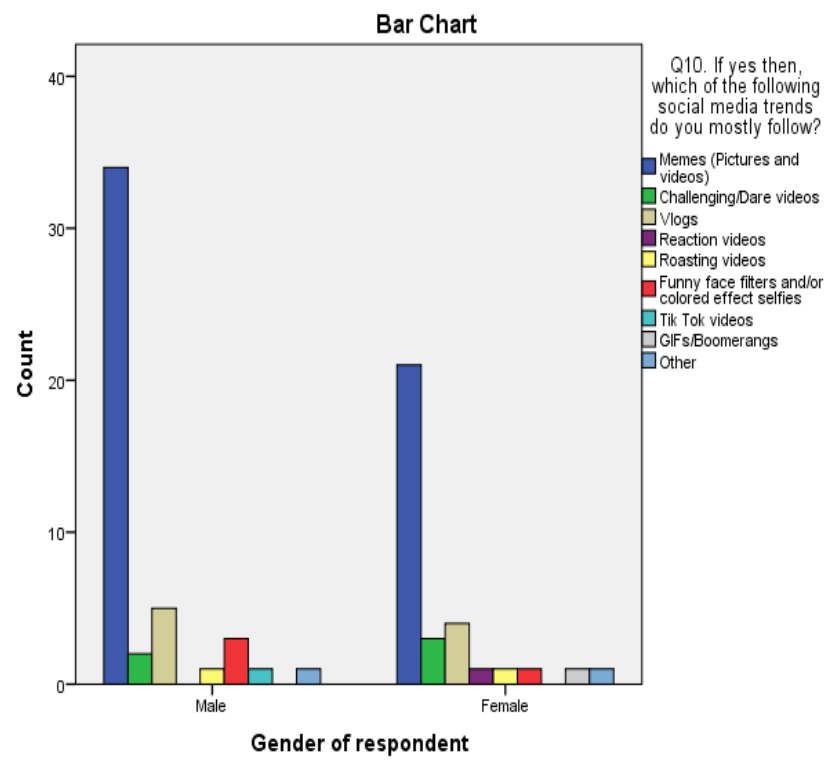

Figure 35

According to table 35 and figure 35, in all of the social media trends "Meme" is the most highly following trend on social media as 55 respondents follow memes including 34 males and 21 females.

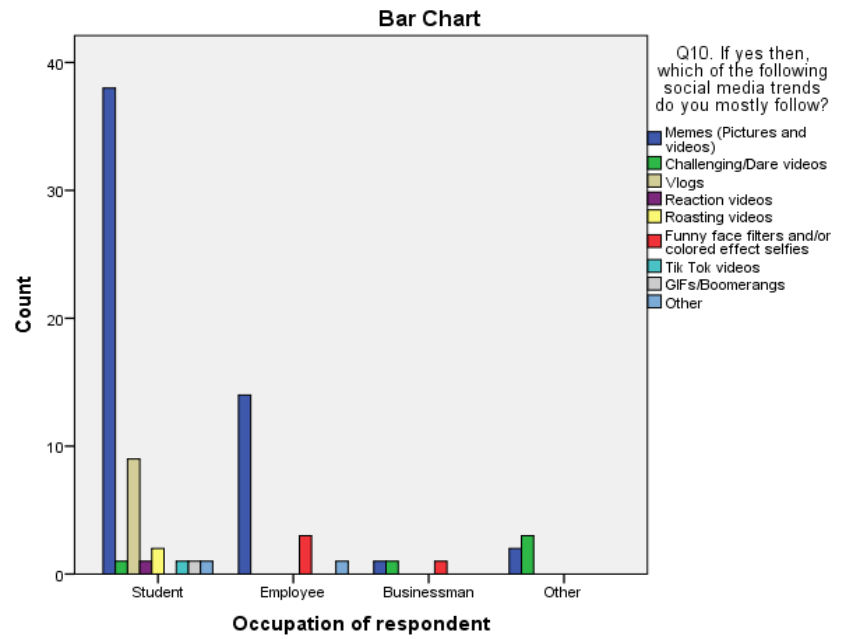

Figure 36

According to the above table and figure, "Meme" is the most highly following trend in all of the trends. Students, employee, businessmen and others like to follow memes the most. Out of 80 respondents, 55 people supported memes including 38 
students, 14 employees, 1 businessman and 2 others.

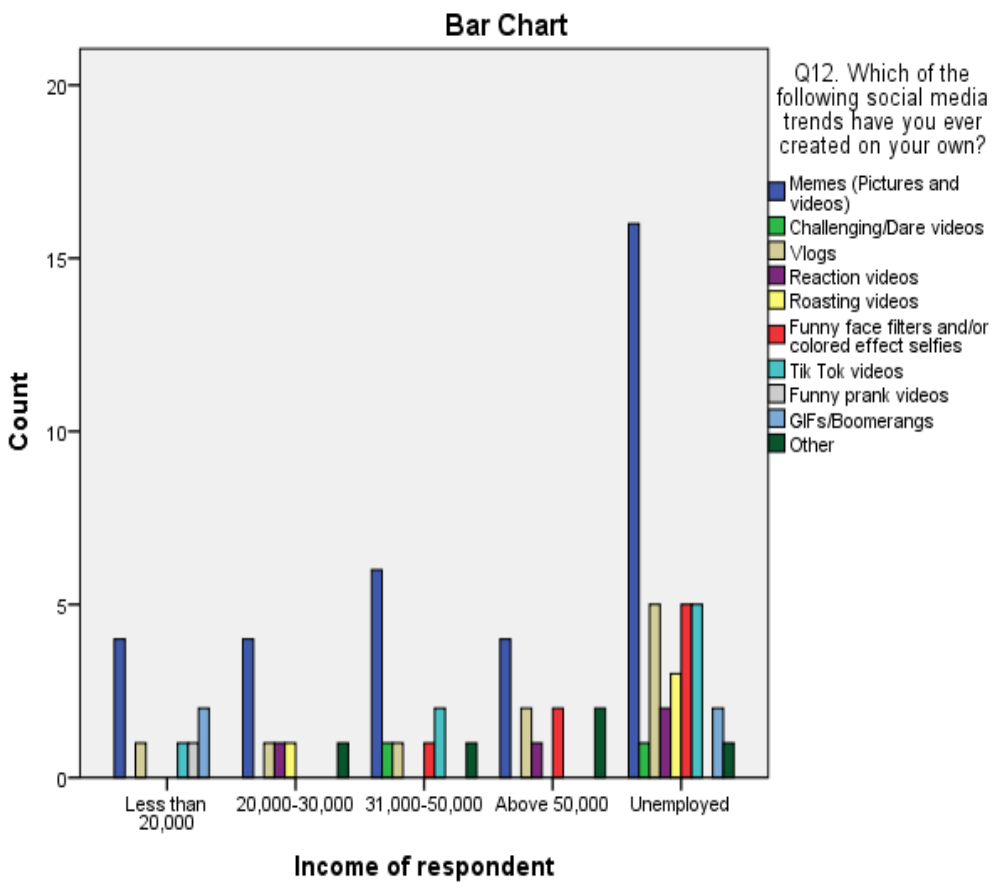

Figure 37

According to table 37 and figure 37, unemployed people are more involved in the following social media trends. Out of 80 respondents, 54 students, 18 employees, 3 businessmen and 5 others follow over all social media trends.

\section{Chi-Square Test Results of Hypothesis}

Table 1

Q27. Do you think that such latest trends running on social media affecting Pakistani youth more in a negative manner?

\begin{tabular}{|l|r|r|rr|}
\hline & Observed N & Expected N & Residual \\
\hline Strongly Agree & 27 & 20.0 & & 7.0 \\
Agree & 26 & 20.0 & 6.0 \\
Neutral & 20 & 20.0 & .0 \\
Disagree & 7 & 20.0 & -13.0 \\
Total & 80 & & & \\
\hline
\end{tabular}


Table 2: Test Statistics

Q27. Do you think that such latest trends running on social media affecting Pakistani youth more in a negative manner?

Chi-Square

Df

Asymp. Sig.

a. 0 cells $(.0 \%)$ have expected frequencies less than 5 . The minimum expected cell frequency is 20.0 .

The results of chi square shows that the $\mathrm{P}$ value of this test is smaller than 0.05 (i.e. 0.005 ) at the calculated value $\mathrm{x} 2=12.700$ with $\mathrm{df}=3$.

Hence, as per the result data seems to be significant. So, H1 "Social media latest trends affect the life of youth more in a negative manner" is accepted and H0 "Social media latest trends affect the life of youth more in a positive manner" is rejected.

Table 3: Q17. Do you consider yourself addicted to social media due to the latest trending videos and memes?

\begin{tabular}{lrr|r} 
& Observed N & Expected N & \multicolumn{2}{|c}{ Residual } \\
Always & 15 & 26.7 & -11.7 \\
Sometimes & 56 & 26.7 & 29.3 \\
Never & 9 & 26.7 & -17.7 \\
Total & 80 & &
\end{tabular}

Table 4 Test Statistics

Q17. Do you consider yourself addicted to social media due to the latest trending videos and memes?

Chi-Square $49.075^{\mathrm{a}}$

Df

Asymp. Sig.

.000

a. 0 cells $(.0 \%)$ have expected frequencies less than 5 . The minimum expected cell frequency is 26.7.

The results of chi square shows that the $\mathrm{P}$ value of this test is smaller than 0.05 (i.e. 0.000 ) at the calculated value $\mathrm{x} 2=49.075$ with $\mathrm{df}=2$.

Hence, as per the result data seems to be significant. So, H2 "The social media addiction rate is increasing due to the latest trend following on social media" is accepted and $\mathrm{H} 0$ "The social media addiction rate is decreasing due to the latest trend following on social media" is rejected. 


\section{DISCUSSION}

In this study two hypothesis were questioned with null hypothesis.

H1: Social media latest trends affect the life of youth more in a negative manner.

H0: Social media latest trends affect the life of youth more in a positive manner.

\section{On the basis of H1, following themes were found after data analysis:} According to the analysis of question 27, a large group of people in the whole population considers that such latest trends running on social media affectingPakistani youth more in a negative manner.

On the basis of $\mathrm{HO}$, following themes were found after data analysis: According to the analysis of question 27, a large group of people in the whole population considers that such latest trends running on social media affecting Pakistani youth more in a negative manner.

$\mathrm{H} 2$ : The social media addiction rate is increasing due to the latest trend following on social media.

$\mathrm{H} 0$ : The social media addiction rate is decreasing due to the latest trend following on social media.

\section{On the basis of $\mathrm{H} 2$, following themes were found after data analysis:}

According to the analysis of question 17, a large group of people consider themselves addicted to social media due to the latest trending videos and memes.

\section{On the basis of $\mathrm{HO}$, following themes were found after data analysis:}

According to the analysis of question 17, a large group of people consider themselves addicted to social media due to the latest trending videos and memes.

The researcher has postulated a study, in which she asked exclusive questions from the participants on "The Inclination of Trend Following of Youth of Pakistan on Social Media", where the targeted audience was the youth of Pakistan who are in between the age of 15-30. The sample of about 80 respondents has taken randomly from the people belonged to different places of Pakistan. This study explains various negative as well as positive aspects of the trends on social media following by the youth these days. According to the analysis of hypothesis related questions, people consider more with the statement that the trends running over social media these days are affecting the life of youth more in a negative manner. Through this study it was found that Trends running over Social Networking Sites are likely to have a negative impact on the youth and youth is getting too much addicted to it because of mandatorily following these trends. By the help of this study, the facts have revealed that most of the people among youth creating and following social media trends for entertainment purposes and they consider it a source of problem escapism in their tension filled lives. Mostly people also make Tik Tok videos and Challenging/Dare videos because they think that it's a great source of becoming famous on social platforms. But they are so much deeply involved in these trending activities that most of the time they sacrifice their sleep and other routine works in order to use social media more than the limits. Due to the limitless following 
of social media trends, the life of youth is negatively affecting as they become mentally and physically weak due to not getting proper sleep. They wake up late in the morning, feel lazy the whole day due to which their day got ruined and also face anxiety issues because of this. The analysis also shows that a large community from the whole population is following memes, because they think that memes are the most interesting and entertaining trend on social media and are quite relatable with their real life things so they enjoy it with their family and friends gathering. Another fact that is highlighted by the cross-tabulation analysis explains that those who are unemployed and do not have jobs or due to the lack of busy routine works, they are more involved in following these trends on social media.

\section{RESULT}

After conducting this study, the researcher has come to the conclusion that social media latest trend following has a negative impact on youth's real life. Youth is seriously influenced by their extreme following habits of trends on social media which they consider a necessary part of their life which is actually not concerned with the reality. Youth give careful considerations and more focus on virtual activities instead of real life. Due to these latest trends on social media, addiction rate of using social media is also increasing among youth. Although social media has a huge affirmative side today, a large number of people say that its negative repercussions could highly overweight its benefits. However, the researcher of this research paper believes that the repercussions of social media latest trends would only happen in those cases when an individual is using it in an excessive amount and preferring to focus more on the online social world instead of real world. The researcher further suggested that social media trends are somehow beneficial as if people learn to use it in manageable levels and if they create a balance between the online social world and real world. Social media websites, applications and platforms could become a great avenue for better physical, mental, emotional, interpersonal; and even spiritual development and also useful for entertainment purposes only if utilization is manageable within the limits. This study might be an important learning piece of information in the particular region for the concentration of the upcoming researchers. This study is beneficial for the higher education's policymakers, the authorities and management teams of social media's various platforms, the trend makers as well as the trend followers of social media and for the youth of present era and up-coming generation to provide them awareness regarding the positive and negative aspects of the trending content on social media. This research is mainly related to the field of Mass Communication and Media Studies, so it will also be beneficial for media practitioners. It will be highly useful for the disciplines of Sociology and Psychology because social media has become the most significant part and parcel of our daily life and it plays a major role in both positive and negative manners in our society. 


\section{REFERENCES}

https://www.internetsociety.org/internet/history-internet/brief-history-internet/ Date: 25th September

Ahmed, S. (2005). Art of Modern Journalism. Anmol Publications PVT. LTD..

Akram, W., \& Kumar, R. (2017). A study on positive and negative effects of social media on society. International Journal of Computer Sciences and Engineering, 5(1), 351-354.

Asur, S., Huberman, B. A., Szabo, G., \& Wang, C. (2011, July). Trends in social media: Persistence and decay. In Fifth international AAAI conference on weblogs and social media.

Ellison, N. B., Steinfield, C., \& Lampe, C. (2007). The benefits of Facebook "friends:" Social capital and college students' use of online social network sites. Journal of computer-mediated communication, 12(4), 1143-1168.

Khurana, N. (2015). The impact of social networking sites on the youth. J Mass Communication Journalism, 5, 285.

Mehdizadeh, S. (2010). Self-presentation 2.0: Narcissism and self-esteem on Facebook. Cyberpsychology, behavior, and social networking, 13(4), 357-364.

Pardo, A. (2013). Social learning graphs: combining social network graphs and analytics to represent learning experiences. International Journal of Social Media and Interactive Learning Environments, 1(1), 43-58.

Poe, M. T. (2010). A History of Communications: Media and Society from the Evolution of Speech to the Internet. Cambridge University Press.

Rideout, V. (2012). Social media, social life: How teens view their digital lives (Common Sense Media's Program for the Study of Children and Media).

Shahjahan, A. T. M., \& Chisty, K. U. (2014). Social Media research and its effect on our society. World Academy of Science, Engineering and Technology International Journal of Information and Communication Engineering, 8(6), 2009-2013.

Sharma, S. (2005). Journalism: communication management;(for PG diploma \& degree courses in journalism \& mass media). Anmol Publ..

Siddiqui, S., \& Singh, T. (2016). Social media its impact with positive and negative aspects. International Journal of Computer Applications Technology and Research, 5(2), 71-75.

Young, B. (2006). A study on the effect of internet use and social capital on the academic performance. Journal of Asian Sociology, 35(1), 107-123. 